
\title{
28 Research Suare \\ Experience and Perspectives of Infection Prevention Staff of the COVID-19 Response in Australian Hospitals
}

Alisha Baswa ( $\sim$ alishabaswa@gmail.com )

Monash University

Andrew Stewardson

Alfred Health

Darshini Ayton

Monash University

Phillip Russo

Monash University

Joseph Doyle

Alfred Health

Research

Keywords: Infection Prevention and Control, Australian Hospitals, COVID-19 OR Coronavirus

Posted Date: September 23rd, 2021

DOI: https://doi.org/10.21203/rs.3.rs-907814/v1

License: (9) This work is licensed under a Creative Commons Attribution 4.0 International License. Read Full License 


\section{Abstract}

Background Hospital infection prevention and control (IPC) staff have played a key role in adapting and implementing jurisdictional COVID-19 policy during the current pandemic. We aimed to describe the experiences of IPC staff in Australian hospitals during the COVID-19 pandemic to inform future pandemic preparedness plans.

Methods A cross-sectional study involving an online survey distributed to IPC practitioners employed in Australian hospitals. Survey content was informed by in-depth interviews, and addressed work conditions, redeployed workforce, personal protective equipment, communication, and guidelines. Participants were recruited through the mailing lists of Australasian College of Infection Prevention and Control and the Australasian Society of Infectious Diseases.

Results We received fully or partially completed responses from 160 participants, including 38 (24\%) and $122(76 \%)$ with nursing and medical backgrounds, respectively. Respondents reported access to sufficient information about PPE $(75 \%, 114 / 152)$, PPE was of sufficient quantity $(77 \%, 117 / 152)$ and was of sufficient quality $(70 \%, 106 / 152)$. Barriers to infection prevention guideline implementation included frequently changing guidelines $(57 \%, 84 / 148)$, timing of updates $(65 \%, 96 / 148)$ and contradictory sources of information $(64 \%, 95 / 148)$. Respondents described a need for better communication channels from government authorities to hospital IPC teams. All respondents described an increase in workload leading to difficulty completing work $(63 \%, 97 / 154)$ and feeling burnt out $(48 \% 74 / 154)$

Conclusions These data identify avoidable barriers to implementation of COVID-19 infection prevention guidance in Australian hospitals. These findings can inform future national preparedness strategies.

\section{Background}

Hospital infection prevention and control (IPC) teams have had a critical role in the COVID-19 response. In Australian hospitals, IPC units most frequently include infection control professionals, who are generally nurses who have undergone further training to specialise in this area, and infectious disease physicians.

(1) This team of professionals are responsible for the health service infection control and prevention program which includes implementation and evaluation of IPC guidelines, education, surveillance, outbreak management and ensuring staff health. (2)

We aimed to describe the experience of infection control professionals and infectious diseases physicians working in infection prevention and control (IPC) units in Australian hospitals during the COVID-19 pandemic. We aimed to capture the barriers and enablers of the response to the pandemic and develop recommendations that inform an ideal response in the future.

\section{Methods}

We conducted an online cross-sectional survey of staff working in IPC teams in Australian hospitals. 


\section{Survey development}

To inform the development of the survey, we conducted a literature review focussing on implementation of infection control policy in the context of an epidemic and performed semi-structured interviews with four infection control professionals from one hospital about their experiences of IPC during COVID-19. The main topic areas identified were; workload, workforce (redeployment of staff into IPC roles), personal protective equipment, communication, guidelines, education and training and outbreak response.

The survey was built using the electronic survey tool Qualtrics (Qualtrics, Provo, USA). It contained 8 domains with a total of 40 questions. The majority of questions were in matrix format. All questions were mandatory with an option of 'I don't know' or 'Not applicable'. The survey was piloted by members of the research team and an external infection control professional.

We conducted this survey in accordance with the CHERRIES checklist. (3)

\section{Recruitment}

Participants were recruited through electronic mailing lists of the relevant colleges; Australasian College of Infection Prevention and Control on the 10th August 2020 and Australasian Society of Infectious Diseases on the 11th August 2020. Reminder emails were sent to both groups two weeks after the initial email to increase survey uptake. The survey was then closed on the 12th September 2020.

\section{Data analysis}

The survey was analysed using Stata version 16 (Statacorp, USA) for descriptive statistics and the free text responses were analysed using content analysis in Microsoft Excel (Version 16.40, 2019 Microsoft Corporation, USA).

\section{Ethics}

Approval was granted by the Alfred Health Human Research Ethics Committee and was registered with the Monash University Human Research Ethics Committee.

\section{Results}

We received 160 responses; 146 complete, 14 incomplete. Respondent characteristics are presented in Table 1. Respondents were predominantly infection control professionals $(126 / 160,76 \%)$, with greater than six years infection prevention experience $(110 / 160,69 \%)$ who were in a leadership role $(116 / 160$, $73 \%$. The majority worked primarily in public metropolitan hospitals within IPC teams containing less than three full time equivalents. We received responses from all states and territories except the Australian Capital Territory, with Victoria and New South Wales being most frequently represented. $34 / 160(21 \%)$ respondents described having experienced a COVID-19 outbreak in their hospital. 
Table 1

Demographics of Participants

\begin{tabular}{|c|c|c|}
\hline & $\mathbf{n}$ & $\%$ \\
\hline \multicolumn{3}{|l|}{ Profession } \\
\hline Physician & 36 & $23 \%$ \\
\hline Physician trainee & 2 & $1 \%$ \\
\hline Infection Control Professional & 122 & $76 \%$ \\
\hline \multicolumn{3}{|l|}{ Years worked in Infection Prevention } \\
\hline$<1$ year & 7 & $4 \%$ \\
\hline $1-5$ & 43 & $27 \%$ \\
\hline $6-10$ years & 43 & $27 \%$ \\
\hline $11-15$ years & 30 & $19 \%$ \\
\hline 16 years or more & 37 & $23 \%$ \\
\hline \multicolumn{3}{|l|}{ Leadership Role } \\
\hline Yes & 116 & $73 \%$ \\
\hline \multicolumn{3}{|l|}{ Full time equivalent (FTE) Infection Prevention staff } \\
\hline$<1$ & 37 & $23 \%$ \\
\hline 1 or 2 & 55 & $34 \%$ \\
\hline 3 or 4 & 32 & $20 \%$ \\
\hline$\geq 5$ & 29 & $18 \%$ \\
\hline Missing & 7 & $4 \%$ \\
\hline \multicolumn{3}{|l|}{ The hospital I primarily work in is located in the following area: } \\
\hline Metropolitan & 98 & $61 \%$ \\
\hline Regional & 32 & $20 \%$ \\
\hline Rural & 30 & $19 \%$ \\
\hline \multicolumn{3}{|l|}{ The hospital I primarily work in is: } \\
\hline Public & 124 & $78 \%$ \\
\hline Private & 32 & $20 \%$ \\
\hline I spend an equal time in both private and public hospitals & 4 & $3 \%$ \\
\hline
\end{tabular}




\begin{tabular}{|c|c|c|}
\hline & $\mathbf{n}$ & $\%$ \\
\hline \multicolumn{3}{|c|}{ The hospital I primarily work in is located in the following state/territory: } \\
\hline VIC & 55 & $34 \%$ \\
\hline NSW & 53 & $33 \%$ \\
\hline QLD & 17 & $11 \%$ \\
\hline NT & 4 & $3 \%$ \\
\hline WA & 19 & $12 \%$ \\
\hline SA & 6 & $4 \%$ \\
\hline TAS & 6 & $4 \%$ \\
\hline \multicolumn{3}{|c|}{ Approximate number of beds at hospital: } \\
\hline$<200$ & 59 & $37 \%$ \\
\hline $200-400$ & 41 & $26 \%$ \\
\hline$>400$ & 60 & $38 \%$ \\
\hline \multicolumn{3}{|c|}{ Approximately number of confirmed COVID-19 inpatients treated at the hospital } \\
\hline 0 & 51 & $32 \%$ \\
\hline $1-10$ & 42 & $26 \%$ \\
\hline $11-25$ & 20 & $13 \%$ \\
\hline$>25$ & 43 & $27 \%$ \\
\hline I don't know & 4 & $3 \%$ \\
\hline \multicolumn{3}{|c|}{ Outbreaks or clusters at the hospital } \\
\hline Yes & 34 & $21 \%$ \\
\hline No & 110 & $69 \%$ \\
\hline I don't know & 2 & $1 \%$ \\
\hline Missing & 14 & $9 \%$ \\
\hline
\end{tabular}

The survey covered the key domains of personal protective equipment (PPE), guidelines, communication, redeployment, training and personal experience.

Personal Protective Equipment 
In general, respondents either 'agreed' or 'strongly agreed' that they had sufficient information regarding PPE $(123 / 152,81 \%)$, and that PPE was available in both sufficient quantity $(117 / 152,77 \%)$ and quality $(106 / 152,70 \%)$ (Fig. 1). There was, however, general agreement that the provision of multiple different brands and models of PPE was the source of concern.

\section{Guidelines}

More than half of respondents agreed or strongly agreed that government guidelines were supported by scientific evidence, they increased the acceptability of local guidelines, they were sufficiently detailed and were clear and unambiguous (Fig. 3).

In contrast to general support for the content of government guidelines, respondents agreed with a number of barriers to their implementation. Among such barriers were the high frequency of guideline modification $(84 / 148,57 \%)$, the release of guideline updates late at night or before the weekend $(96 / 148$, $65 \%)$, and contradictory information from professional societies $(95 / 148,64 \%)$, other hospitals $(59 / 148$, 40\%), news media (73/148, 49\%), and social media (81/148 55\%) (Fig. 2).

\section{Communication}

The four stakeholder groups identified were government, hospital executive, hospital IPC and hospital staff. The channels that infection prevention thought that had an excellent flow of information was within the IPC team and IPC to hospital executive. The communication channel that infection prevention thought was the worst was the government to IPC (Fig. 4).

\section{Redeployment}

Ninety-two respondents indicated that redeployment occurred at their hospital. The respondents identified written standard operating procedures, formal training, and competency with computing skills as being more important for successful redeployment of the IPC team than pre-existing IPC knowledge.

\section{Personal Experience}

The greatest concern for respondents was an outbreak occurring at the hospital they worked in and least concerned about acquiring COVID-19 themselves. All respondents reported an increase. In workload. The majority of respondents found that the increased workload prevented from completing work (97/154 $63 \%$ ) and difficulty in completing routine infection prevention work $86 / 15456 \%$ ). The then lead to feelings of burn out to a great extent in respondents (74/154 48\%).

\section{Discussion}

This is the first Australian study to explore the experience of IPC teams in response to the COVID-19 pandemic. Hospital infection control policies are part of a system of integrated policies and practices that aims to control disease transmission, as was seen in the response to COVID-19 in many countries. (4) (5, 
6) This study identified through interviews and surveys key components of infection control implementation strategies that could be improved upon for future outbreaks, with a focus on the themes of PPE, guidelines, communication and redeployment strategies. We have synthesised the findings of this survey into a series of recommendations (Box 1).

News outlets within Australia regularly commented that healthcare workers have inadequate access to PPE. (7) This is consistent with surveys of frontline healthcare workers in other countries.(8) (9) In contrast, our data suggests that hospital infection control teams believed that their hospitals had access to sufficient quantity and quality of PPE. This discrepancy may, to a large extent, be explained by the fact that while sufficient PPE was generally available in Australian hospitals to implement the guidelines as they were written (i.e. a reliance on surgical masks for care of COVID-19), there were prominent calls for increasing use of P2/N95 respirators by frontline healthcare workers. (10) A finding that was not reported during previous epidemics was that the provision of different brands and/or models of PPE caused concern in hospital staff. This emphasises how limiting the amount of changes within the constantly shifting environment of a pandemic can lessen concern for hospital staff.

Previous studies identified that a lack of adequate implementation of guidelines, constant guideline changes and alternative sources of information were challenges associated with guidelines $(11)(12,13)$. We found that despite these learnings from previous epidemics, Australian hospitals continue to face similar challenges. In addition to this, our study identified that updates to government guidelines published out of hours when there were fewer IPC staff to adapt their own internal hospital guideline was also a barrier to implementation.

This study identified that the four stakeholder groups for the COVID-19 response in hospitals were government, hospital executive, hospital IPC teams and hospital staff. While there was good communication within IPC teams and from IPC teams to hospital executive there was a perceived poor quality of communication from government to hospital executive and IPC teams. Lack of feedback routes from healthcare workers to policymakers was previously identified as an issue in the public inquiry conducted by Canada into the SARS epidemic. (14)

This study identified that written standard operating procedures were the most useful tool for successful redeployment. So far there are no studies investigating the effect of redeployment during COVID-19. We also identified that respondents to this survey were more concerned about an outbreak occurring at their hospital rather than acquiring COVID-19 themselves. This could be because the respondents of the survey were within working age range and the majority of deaths within Australia have been reported in those 70 years old and above.(15)

Given that this cohort will continue to be an integral part of the COVID-19 response, and responses to future pandemics, we suggest that these data should be used to inform future pandemic planning. This survey has national representation from different jurisdictions and types of hospitals. This study was conducted during the pandemic ensuring that there was no recency bias. Notwithstanding the uniqueness, this project has several limitations. First, is the small sample size relative to the total number 
of potentially eligible individuals, which renders the results vulnerable to selection bias. The participation rate may be explained by the fact that this survey was conducted during the pandemic, when IPC staff were time poor and might not have been available to complete the survey. Finally, these results - by design - only represent the perspective of IPC staff. Within the COVID-19 response there are many different stakeholders involved from frontline healthcare workers to operational managers within the hospital. While the recommendations expressed in these results might help IPC staff it might not be feasible to achieve due to constraints within different areas of the hospital.

\section{Conclusion}

With this study, we have aimed to ensure that the lessons learnt during the course of the COVID-19 pandemic are not forgotten, but that they are instead leveraged for the benefit of our future pandemic preparedness.

\section{Declarations}

\section{Ethics approval and consent to participate:}

Low risk approval provided by Alfred Health project number 303/20 on 22/5/2020

\section{Consent for publication:}

Not applicable

\section{Availability of data and materials:}

All data generated or analysed during this study are included in this published article [and its supplementary information files].

\section{Competing interests:}

The authors declare that they have no competing interests

\section{Funding:}

NA

\section{Authors' contributions:}

The manuscript was primarily written by Alisha Baswa. All authors contributed to the editing of the manuscript.

\section{References}


1. Hall L, Halton K, Macbeth D, Gardner A, Mitchell B. Roles, responsibilities and scope of practice: describing the 'state of play' for infection control professionals in Australia and New Zealand. Healthcare infection. 2015;20(1):29-35.

2. Hale R, Powell T, Drey NS, Gould DJ. Working practices and success of infection prevention and control teams: a scoping study. J Hosp Infect. 2015;89(2):77-81.

3. Eysenbach G. Improving the quality of Web surveys: the Checklist for Reporting Results of Internet ESurveys (CHERRIES). J Med Internet Res. 2004;6(3):e34.

4. Chang YT, Lin CY, Tsai MJ, Hung CT, Hsu CW, Lu PL, et al. Infection control measures of a Taiwanese hospital to confront the COVID-19 pandemic. Kaohsiung Journal of Medical Sciences.36(5):296304.

5. Kang J, Jang YY, Kim J, Han SH, Lee KR, Kim M, et al. South Korea's responses to stop the COVID-19 pandemic. American Journal of Infection Control.48(9):1080-6.

6. Tarantini G, Masiero G, Nai Fovino L. Impact of a 10 Rules Protocol on COVID-19 Hospital-Related Transmission: Insights From Padua University Hospital, Italy. Circulation: Cardiovascular Interventions.13(5):e009279.

7. Victoria competing with. rest of the world for PPE during coronavirus pandemic, Premier Dan Andrews says [press release]. ABC: ABC; 2020.

8. Iqbal MR, Chaudhuri A. COVID-19: Results of a national survey of United Kingdom healthcare professionals' perceptions of current management strategy - A cross-sectional questionnaire study. Int J Surg. 2020;79:156-61.

9. Savoia E, Argentini G, Gori D, Neri E, Piltch-Loeb R, Fantini MP. Factors associated with access and use of PPE during COVID-19: A cross-sectional study of Italian physicians. PLoS One. 2020;15(10):e0239024.

10. .

11. Yen MY, Lin YE, Su IJ, Huang FY, Huang FY, Ho MS, et al. Using an integrated infection control strategy during outbreak control to minimize nosocomial infection of severe acute respiratory syndrome among healthcare workers. J Hosp Infect. 2006;62(2):195-9.

12. Moore DM, Gilbert M, Saunders S, Bryce E, Yassi A. Occupational Health and Infection Control Practices -Related to Severe Acute Respiratory Syndrome Health' Care Worker Perceptions. AAOHN Journal. 2005;53(6):257-66.

13. Rambaldini G, Wilson K, Rath D, Lin Y, Gold WL, Kapral MK, et al. The impact of severe acute respiratory syndrome on medical house staff: a qualitative study. J Gen Intern Med. 2005;20(5):3815.

14. Campbell THMJA. The SARS Commission: Spring of Fear Ontario. 2006.

15. Australia Co. COVID-19 deaths by age group and sex. In: Health Do, editor. health.gov.au2021.

\section{Figures}


Figures 1 to 4 are not available with this version.

\section{Box}

Box 1 is not available with this version. 